\title{
Electrical Properties of Ultrathin Platinum Films by Plasma- Enhanced Atomic Layer Deposition
}

Hyo Jin K. Kim, ${ }^{*}{ }^{\dagger}$ Kirsten E. Kaplan, ${ }^{\dagger}$ Peter Schindler, ${ }^{\ddagger}$ (๑) Shicheng Xu, ${ }^{\dagger}$ Martin M. Winterkorn, ${ }^{\dagger}$ David B. Heinz,,$^{\dagger}$ Timothy S. English, ${ }^{\dagger}$ J. Provine, ${ }^{\dagger}$ Fritz B. Prinz, ${ }^{\dagger}$ and Thomas W. Kenny ${ }^{\dagger}$

${ }^{\dagger}$ Mechanical Engineering Department and ${ }^{\ddagger}$ Electrical Engineering Department, Stanford University, Stanford, California 94305, United States

\section{Supporting Information}

ABSTRACT: The ability to deposit thin and conformal films has become of great importance because of downscaling of devices. However, because of nucleation difficulty, depositing an electrically stable and thin conformal platinum film on an oxide nucleation layer has proven challenging. By using plasmaenhanced atomic layer deposition (PEALD) and $\mathrm{TiO}_{2}$ as a nucleation layer, we achieved electrically continuous PEALD platinum films down to a thickness of $3.7 \mathrm{~nm}$. Results show that

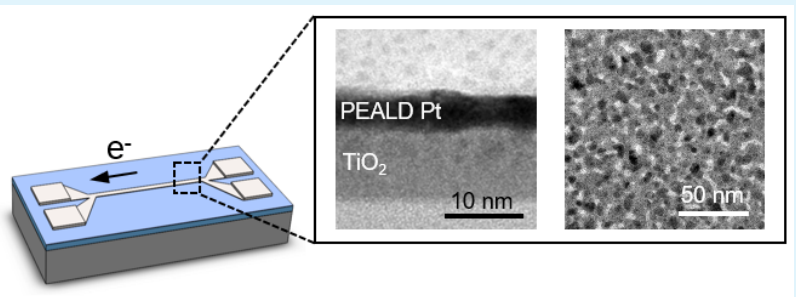
for films as thin as $5.7 \mathrm{~nm}$, the Mayadas-Shatzkes (MS) model for electrical conductivity and the Tellier-Tosser model for temperature coefficient of resistance hold. Although the experimental values start to deviate from the MS model below $5.7 \mathrm{~nm}$ because of incomplete Pt coverage, the films still show root mean square electrical stability better than $50 \mathrm{ppm}$ over time, indicating that these films are not only electrically continuous but also sufficiently reliable for use in many practical applications.

KEYWORDS: thin film, platinum, plasma-enhanced atomic layer deposition, size effect, electrical conductivity, temperature coefficient of resistance

\section{INTRODUCTION}

Modern day electronic devices are moving toward 3D architectures with high aspect ratios in order to push the lower limit of device sizes. ${ }^{1-4}$ This downscaling of devices necessitates not only thin films but also conformal deposition on complex geometries. Platinum has attracted considerable attention for thin-film applications in micro- and nanoelectronic devices because of its chemical inertness, high work function, and excellent electrical properties, including a linear temperature coefficient of resistance (TCR) over a wide temperature range. $^{5-9}$ However, the use of $\mathrm{Pt}$ in devices has been somewhat limited until recently, both because of cost as well as limitations caused by the directionality of conventional Pt deposition techniques such as physical vapor deposition. ${ }^{10}$ Therefore, solving the problem of how to deposit conformal, ultrathin, and electrically stable Pt films is essential for future devices.

The development of thermal atomic layer deposition ( $t$ ALD) allows precise control of thickness and high conformality on complex 3D architectures. ${ }^{11-15}$ However, even with $\mathrm{t}$-ALD there are limits to the attainable film thickness because material-dependent nucleation difficulties prevent continuous films below a certain number of t-ALD cycles. ${ }^{16-19}$ $\mathrm{Pt}$ is one of the materials known to present nucleation challenges with $\mathrm{t}$-ALD. ${ }^{20}$ The high surface energy of Pt leads to Volmer-Weber (VW) growth, forming islands at the early stages of nucleation. ${ }^{21,22}$ This growth behavior sets a lower limit on the minimum closed-film thickness, as these Pt islands must grow large enough to connect to neighboring islands before the film becomes continuous. ${ }^{23}$ Thus, one way of depositing the thinnest possible continuous $\mathrm{Pt}$ films is by maximizing the number of nucleation sites, such that adjacent islands are closer and can merge at a lower cycle count.

Previous research has explored two very different approaches to increase the number of nucleation sites. The first approach explores the use of different nucleation layers such as $\mathrm{W}^{22}$ $\mathrm{Al}_{2} \mathrm{O}_{3}{ }^{19,24,25} \mathrm{TiO}_{2}{ }^{26}$ or $\mathrm{STO}^{27}$ with t-ALD. The thinnest resulting $\mathrm{Pt}$ is $1.5 \mathrm{~nm}$ on tungsten $(\mathrm{W})$. However, as $\mathrm{W}$ itself is conductive, the resulting stack is not feasible for use in ultrathin electronic layers because it would degrade the desirable electrical properties of platinum. The other approach uses plasma-enhanced ALD (PEALD), a modified version of $t$ ALD that replaces the co-reactant with plasma. Plasma mitigates some of the nonideal nucleation behavior because of its higher reactivity. ${ }^{12,28,29}$

In this paper, recognizing the individual benefits of PEALD and different nucleation layers, we combined the two approaches: using PEALD in combination with $\mathrm{Al}_{2} \mathrm{O}_{3}$ and $\mathrm{TiO}_{2}$ as a nucleation layer. Our first finding is that metal oxides that are capable of reduction can serve as good nucleation layers to deposit thinner Pt films. The second finding is that PEALD Pt films' surfaces are partly specular and subject to low

Received: December 3, 2018

Accepted: February 1, 2019

Published: February 1, 2019 
grain boundary scattering, which leads to higher conductivity based on fitting the Mayadas-Shatzkes (MS) model. ${ }^{30} \mathrm{Pt}$ films down to $5.7 \mathrm{~nm}$ fit the same MS curve well. The Pt film's TCR values were then further characterized with the Tellier-Tosser model. ${ }^{31}$ Whereas films below $5.7 \mathrm{~nm}$ deviated from the MS curve because of incomplete coverage, we successfully deposited electrically continuous Pt films as thin as $3.7 \mathrm{~nm}$ with an electrical conductivity of $3.78 \times 10^{6} \Omega^{-1} \mathrm{~m}^{-1}$ and TCR of $0.84 \times 10^{-3} 1 /{ }^{\circ} \mathrm{C}$ utilizing $\mathrm{TiO}_{2}$ as a nucleation layer. These films had a root mean square (RMS) electrical stability better than $50 \mathrm{ppm}$, proving their viability for device applications.

\section{EXPERIMENTAL SECTION}

2.1. Sample Preparation. Prior to depositing oxide nucleation layers, p-doped $\mathrm{Si}(100)$ wafers, with resistivity of $0.1-0.9 \Omega \mathrm{m}$, were RCA cleaned and thermal $\mathrm{SiO}_{2}$ layers of $\sim 180 \mathrm{~nm}$ (wet oxidation, $900{ }^{\circ} \mathrm{C}, 1 \mathrm{~h} 34 \mathrm{~min}$ ) were grown to serve as an electrical insulation layer between the Si substrate and Pt. On each wafer, $\sim 11 \mathrm{~nm}$ of one of the two nucleation layers of interest, $\mathrm{Al}_{2} \mathrm{O}_{3}$ and $\mathrm{TiO}_{2}$, were deposited on top of the thermal oxide using PEALD. Pt was deposited on samples with both nucleation layers simultaneously, with the number of PEALD Pt cycles varying from 10 to 250 to achieve different thicknesses. All ALD films in this paper were deposited in an ALD reactor (Fiji, Cambridge Nanotech/Veeco) equipped with a remote inductively coupled plasma. The precursors used for the metal oxide deposition were trimethylaluminum and tetrakis(dimethylamido)titanium(IV), for $\mathrm{Al}_{2} \mathrm{O}_{3}$ and $\mathrm{TiO}_{2}$, respectively, with $\mathrm{O}_{2}$ plasma as the co-reactant. For Pt depositions (methylcyclopentadienyl)trimethylplatinum $\left(\mathrm{MeCpPtMe}_{3}\right)$ was used with $\mathrm{O}_{2}$ plasma as a reactant. Before every film deposition, samples went through an in-situ $\mathrm{O}_{2}$ plasma clean at $300 \mathrm{~W}$ (for detailed conditions refer to the Supporting Information, Figure S1). To fabricate electrical test structures, Pt beams $(4 \mu \mathrm{m} \times 996 \mu \mathrm{m})$ were patterned by ion milling (Nanoquest Research Ion Beam Milling System, Intlvac), with $50 \mathrm{~nm}$ thick Pt bond pads evaporated (Kurt J. Lesker Co.) and patterned by lift-off (Figure 1a).

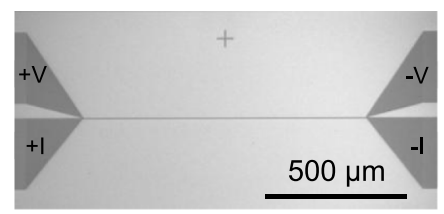

(a)

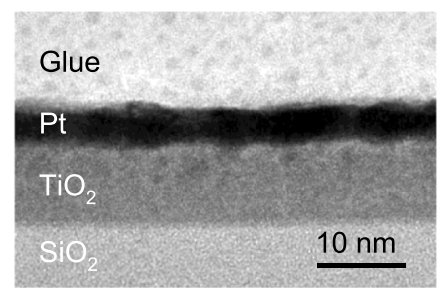

(b)

Figure 1. (a) Scanning electron microscopy image of electrical measurement test structure; (b) TEM image confirming the thickness of the thinnest continuous Pt film measured with XRR $(3.7 \mathrm{~nm})$.

2.2. Material Characterization. To study the nucleation phase, transmission electron microscopy (TEM) grids (PELCO Silicon Dioxide Support, $18 \mathrm{~nm}$, Ted Pella, Inc.) attached to a Si wafer with carbon paste (Electrodag 502, Ted Pella, Inc.) were loaded prior to PEALD of oxides and Pt. bright and dark field micrographs were taken using a transmission electron microscope (FEI Tecnai G2 F20 X-TWIN FEG, $200 \mathrm{kV})$. Pt coverage, defined as Pt coverage (\%) = $\frac{\text { area covered by } \mathrm{Pt}\left(\mathrm{nm}^{2}\right)}{\text { image area }\left(\mathrm{nm}^{2}\right)} \times 100$, was calculated using bright field micrographs post-processed with a low-pass Wiener filter (5-pixel averaging) and thresholding. Additionally, cross sections of the samples were prepared following the conventional TEM sample preparation procedure described by Strecker et al. ${ }^{32}$ (Figure 1b). Metal oxide thicknesses were measured with Spectroscopic Ellipsometry (M 2000, J.A.Woollam Co.), and Pt thicknesses were evaluated with X-ray reflectivity (XRR, X'Pert Pro, PANalytical) (see the Supporting Information, Figure S2). Platinum roughness was measured with noncontact mode atomic force microscopy (AFM, XE100, Park Systems). X-ray photoelectron spectroscopy (XPS, PHI 5000 VersaProbe III, Ulvac-PHI, Inc.) was used to confirm the material composition. Crystallinity of Pt films was confirmed with high-resolution TEM, selected area diffraction patterns, and grazing incident X-ray diffraction (X'Pert Pro, PANalytical) patterns (see the Supporting Information, Figure S3). Surface hydroxyl concentration was assessed using the water contact method on a contact angle goniometer (model 290, ramé-hart).

2.3. Electrical Measurements. Electrical conductivity and wafer scale resistivity of as-deposited $\mathrm{Pt}$ were measured using a resistivity mapping system (OmniMap RS35c, KLA/Tencor). The TCR was measured from 30 to $100{ }^{\circ} \mathrm{C}$ using a semiconductor device analyzer (B100A, Agilent Technologies) in a probe station (CM170-6, Signatone) installed with a high-temperature chuck (S-1060H-4TP, QuieTemp). RMS film stability measurements were made in a temperature-controlled chamber using a four-point probe (Keithley $6221 / 2182 \mathrm{~A}$, Keithley) and delta current reversal techniques to minimize voltage errors from the leads and thermal EMFs. Electrical stability was determined from resistance measurements collected continuously for $30 \mathrm{~min}$, and calculated as $R_{\mathrm{RMS}}(\mathrm{ppm})=$ $\sqrt{\sum_{i=1}^{n}\left(\frac{r_{i}-\underline{r}}{\underline{r}}\right)^{2}} \times 10^{6}$, where each $r_{i}$ is an individual resistance measurement, $n$ is the number of measurements collected, and $\underline{r}$ is the mean resistance.

2.4. Theoretical Models. Once the grain size and thickness of a metal film drop below the bulk metal's electron mean free path (MFP), electron scattering at the surface and grain boundaries causes changes in the film's electrical properties. This effect is known as the size effect. The MS model, an extension of the Boltzmann equation that accounts for surface and grain boundary scattering, predicts reductions in the electrical conductivity of thin metals by treating grain boundaries as a periodic potential barrier. ${ }^{30}$ The MS model gives the film conductivity $\sigma_{\mathrm{f}}$ as

$$
\begin{aligned}
\sigma_{\mathrm{f}}= & \sigma_{\mathrm{o}}\left\{F(\alpha)-\frac{6}{\pi k_{0}}(1-p) \int_{0}^{\pi / 2} \mathrm{~d} \phi \int_{1}^{\infty} \mathrm{d} t \frac{\cos ^{2} \phi}{H^{2}(t, \phi)}\right. \\
& \left.\left(\frac{1}{t^{3}}-\frac{1}{t^{5}}\right) \frac{1-\mathrm{e}^{-k_{0} H(t, \phi)}}{1-p \mathrm{e}^{-k_{0} H(t, \phi)}}\right\}
\end{aligned}
$$

where

$$
\begin{aligned}
& F(\alpha)=1-\frac{3}{2} \alpha+3 \alpha^{2}-3 \alpha^{3} \ln \left(1+\frac{1}{\alpha}\right), \\
& \quad H(t, \phi)=1+\frac{\alpha}{\cos \phi\left(1-1 / t^{2}\right)^{1 / 2}}, \quad \alpha=\frac{l_{0}}{d} \frac{R}{1-R}, k_{0}=\frac{l_{\mathrm{f}}}{l_{0}},
\end{aligned}
$$

$\sigma_{\mathrm{o}}$ is the bulk Pt conductivity, $l_{0}$ is the electron MFP for bulk Pt $\left(l_{0}=\right.$ $22.4 \mathrm{~nm}),{ }^{33} l_{\mathrm{f}}$ is the film thickness, $d$ is the average grain size, $R$ is the grain boundary reflection coefficient, and $p$ is the specular reflection coefficient. The average in-plane grain size was approximated based on dark-field TEM images (see Supporting Information, Figure S4). The constants $p$ and $R$ are fit to the experimental data. The film TCR $\beta_{\mathrm{f}}$ is given by the Tellier-Tosser model ${ }^{31}$ as

$$
\beta_{\mathrm{f}}=\beta_{0}\left(1+\frac{G(\alpha)}{F(\alpha)}\right) \frac{k_{0}}{k_{0}+\frac{3}{8} F(\alpha)(1-p)}
$$




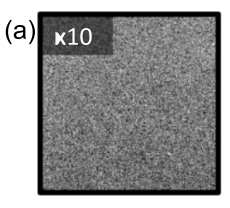

(b) $\times 10$

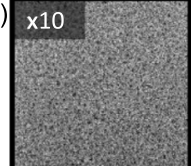

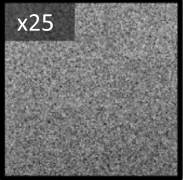

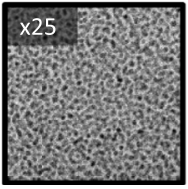

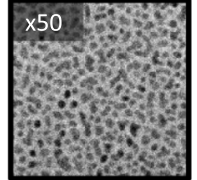

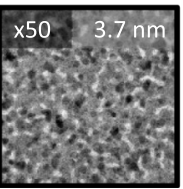

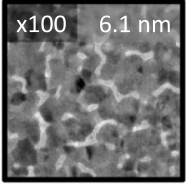

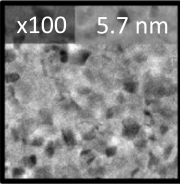

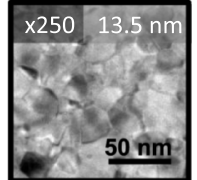

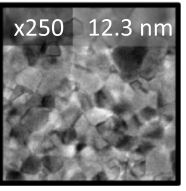

Figure 2. Planar view TEM image showing morphology evolution of PEALD Pt on (a) $\mathrm{Al}_{2} \mathrm{O}_{3}$ and (b) $\mathrm{TiO}_{2}$ from 10 to 250 cycles. Numbers in the upper left denote the number of cycles. For electrically continuous films, Pt thickness is given in the upper right corner.

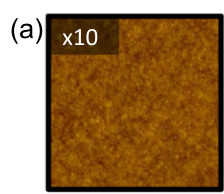

(b) $\times 10$

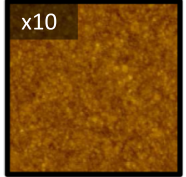

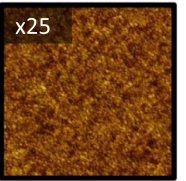

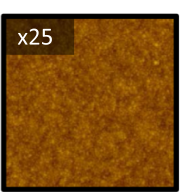

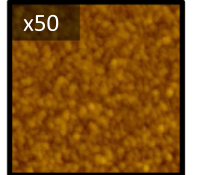
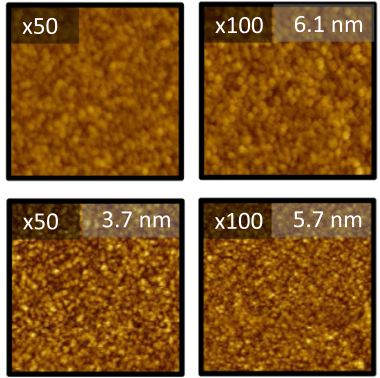

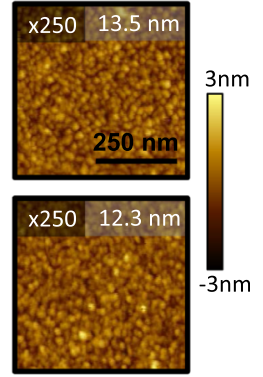

Figure 3. AFM images showing morphology evolution of PEALD Pt on (a) $\mathrm{Al}_{2} \mathrm{O}_{3}$ and (b) $\mathrm{TiO}_{2}$ from 10 to 250 cycles. Numbers in the upper left denote the number of Pt cycles. For electrically continuous films, Pt thickness is given in the upper right corner.

where $G(\alpha)=-\frac{3}{2} \alpha+6 \alpha^{2}-\frac{3 \alpha^{3}}{1+\alpha}-9 \alpha^{3} \ln \left(1+\frac{1}{\alpha}\right)$ and $\beta_{0}$ is the TCR of bulk Pt.

\section{RESULTS AND DISCUSSION}

\subsection{Nucleation Behavior of Platinum on Different} Nucleation Layers. By investigating the nucleation behavior of $\mathrm{Pt}$ on two different nucleation layers, $\mathrm{Al}_{2} \mathrm{O}_{3}$ and $\mathrm{TiO}_{2}$, we found that the Pt film's morphology differs between the two layers throughout the nucleation process (Figures 2 and 3 ). Whereas Pt exhibits VW growth behavior on both nucleation layers as reported in the literature ${ }^{28,34}$ (and confirmed by TEM, Figure S5), the number of PEALD cycles required to reach crystallite coalescence differs significantly between $\mathrm{Al}_{2} \mathrm{O}_{3}$ and $\mathrm{TiO}_{2}$. RMS roughness will be largest around the time individual islands coalesce, ${ }^{35}$ as this is when the film height variation is at a maximum as each individual crystallite is tall when the gaps between crystallites remain at nearly the level of the nucleation layer. Using this approximation, we can conclude that the Pt films are nearly at the coalescing point at around 50 and $150 \mathrm{Pt}$ cycles on $\mathrm{TiO}_{2}$ and $\mathrm{Al}_{2} \mathrm{O}_{3}$, respectively (Figure 4).

The difference in the coalescing point is a result of more $\mathrm{Pt}$ islands nucleating on $\mathrm{TiO}_{2}$ as compared to $\mathrm{Al}_{2} \mathrm{O}_{3}$, which suggests that more nucleation sites were available on $\mathrm{TiO}_{2}$. To quantitatively confirm this, the number of nucleation sites was estimated by the percentage of Pt coverage (Figure 5) on TEM images, as this is proportional to the size and number of crystalline islands and therefore to the number of reaction sites on the nucleation layer. Whereas there are Pt particles on both nucleation layers after 10 cycles, $\mathrm{TiO}_{2}$ has $\sim 3$ times more $\mathrm{Pt}$ coverage than $\mathrm{Al}_{2} \mathrm{O}_{3}$. At 25 cycles of $\mathrm{Pt}$, the difference is even more pronounced with $\mathrm{TiO}_{2}$ having $\sim 50$ times more $\mathrm{Pt}$ coverage than $\mathrm{Al}_{2} \mathrm{O}_{3}$. At this cycle number, the $\mathrm{Pt}$ particles on $\mathrm{TiO}_{2}$ are beginning to coalesce and form the worm-like structure characteristic of the initial formation of a continuous

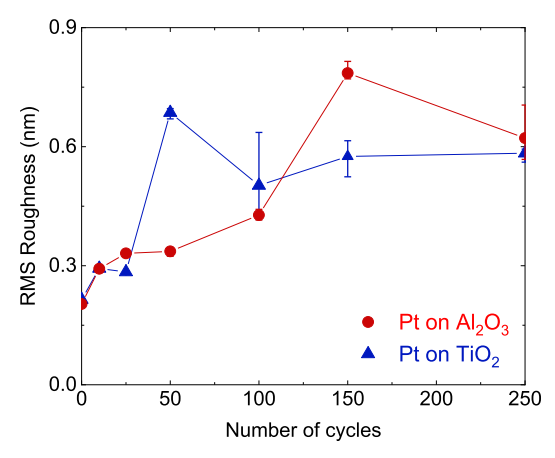

Figure 4. RMS roughness versus number of Pt PEALD cycles on $\mathrm{Al}_{2} \mathrm{O}_{3}$ and $\mathrm{TiO}_{2}$. These values were collected from Figure 3.

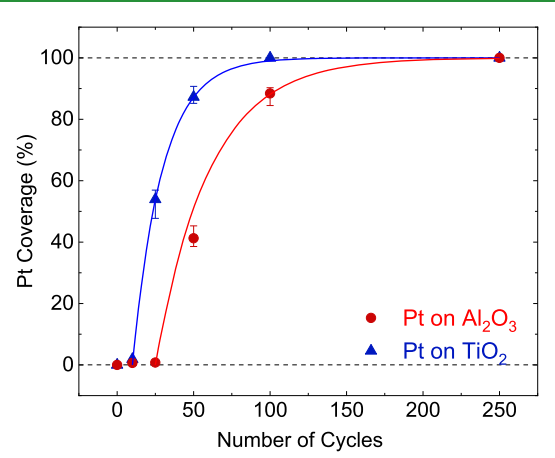

Figure 5. Pt coverage versus number of PEALD Pt cycles for both nucleation layers. Three $170 \mathrm{~nm} \times 85 \mathrm{~nm}$ TEM images were processed to calculate the coverage for each data point.

film. In contrast, the Pt particles remain isolated on the $\mathrm{Al}_{2} \mathrm{O}_{3}$ nucleation layer. This trend continues with increasing numbers of PEALD Pt cycles; at 100 cycles the Pt has reached full coverage on $\mathrm{TiO}_{2}$, whereas on $\mathrm{Al}_{2} \mathrm{O}_{3}$ it is still coalescing. This shows how, even though both films start with VW island 
growth, $\mathrm{TiO}_{2}$ enables a continuous film at such low thicknesses: the higher density of nucleating $\mathrm{Pt}$ particles on $\mathrm{TiO}_{2}$ results in particles meeting and coalescing into a continuous film at a lower cycle count.

It is interesting to note that the coverage points can be fit to cycle count to yield an estimate of the amount of the exposed nucleation layer covered by $\mathrm{Pt}$ per cycle. If we assume 10 and 25 cycles of nucleation delay for $\mathrm{TiO}_{2}$ and $\mathrm{Al}_{2} \mathrm{O}_{3}$, respectively, then with every cycle $5 \%$ of exposed $\mathrm{TiO}_{2}$ and $2.8 \%$ of exposed $\mathrm{Al}_{2} \mathrm{O}_{3}$ are covered with Pt. This means the rate of nucleation is approximately 1.75 times faster on $\mathrm{TiO}_{2}$. This trend in the rate of nucleation is consistent within a major portion of the PEALD temperature window of $200-270{ }^{\circ} \mathrm{C}$.

The significantly different nucleation behavior observed on the two nucleation layers can be explained from the unique half-reactions of the Pt precursor. Previous research on Pt ALD growth atop a continuous $\mathrm{Pt}$ surface showed that during the first half-reaction, when $\mathrm{MeCpPtMe}_{3}$ is pulsed into the chamber, the precursor reacts with exposed oxygen atoms on the surface and undergoes dehydrogenation. Oxygen, introduced for the second half-reaction, serves two purposes. First, it removes the carbonaceous layer left from the first halfreaction. In addition, some of the oxygen is chemisorbed by the Pt surface, thereby creating reaction sites for the next cycle. The oxygen pulse can be either $\mathrm{O}_{2}$ gas, in the case of $t$-ALD, or $\mathrm{O}_{2}$ plasma, for PEALD. Growth per cycle is higher for PEALD because the plasma more readily oxidizes the surface $\mathrm{Pt}^{28}$ This importance of surface oxygen atoms for Pt ALD growth on continuous films can also explain growth at the nucleation stage.

Because hydroxyl bonds serve as nucleation sites for $\mathrm{Pt},{ }^{36} \mathrm{Pt}$ nucleation is higher when more hydroxyl bonds are available on the nucleation surface. ${ }^{26}$ The relative concentration of surface hydroxyl bonds on $\mathrm{TiO}_{2}$ and $\mathrm{Al}_{2} \mathrm{O}_{3}$ was assessed by measuring the water contact angle (see the Supporting Information, Figure S6). Both measured contact angles are below the resolution limit of $4.5^{\circ}$. This minimal difference in angle between two films is not enough to explain the significant difference in nucleation rate.

We speculate that the nucleation difference can be further explained by the fact that $\mathrm{TiO}_{2}$ is more easily reduced than $\mathrm{Al}_{2} \mathrm{O}_{3}{ }^{37}$ This allows $\mathrm{TiO}_{2}$ to act as an oxygen reservoir, creating many more nucleation sites for $\mathrm{MeCpPtMe}_{3}$ than $\mathrm{Al}_{2} \mathrm{O}_{3}$.

3.2. Electrical Conductivity, TCR, and Stability of Platinum Films. The electrical properties of these films are subject to the size effect as the film thicknesses are significantly smaller than the electron MFP of Pt. As a result, the electrical conductivity is reduced by as much as $83 \%$ for the $4 \mathrm{~nm}$ films as compared to bulk values, as shown in Figure 6.

Because we are using one equation, the MS model, to fit two unknowns, $p$ and $R$, additional insight is needed to ensure the fitted values make physical sense. We measured the RMS roughness of the Pt surface (Figure 4) to be between 0.4 and $0.7 \mathrm{~nm}$. This low level of roughness indicates that the $\mathrm{Pt}$ surface will not be completely diffusive, meaning that the platinum surface is partly specular. We expect $R$ to be between 0.1 and 0.9 , which is typical for polycrystalline materials. $^{7,24,33,38-40}$ Given these bounds, we found $p=0.5$ and $R$ $=0.1$ best fit the MS model. These values correspond to lowsurface and grain-boundary scattering, suggesting that our films are of high quality. To verify that there are no residual impurities from the precursor in our Pt films we employed XPS

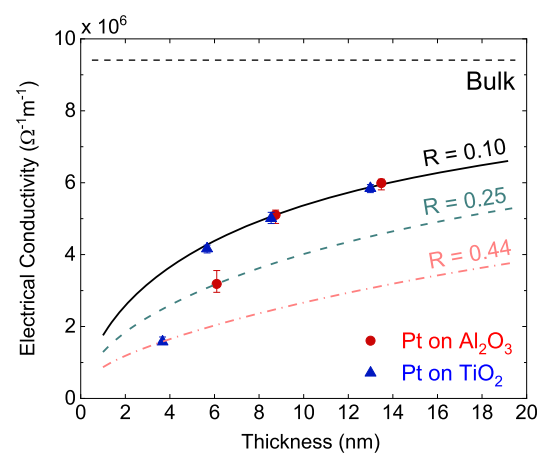

Figure 6. Experimental value and theoretical curves (with $p=0.5$ ) for electrical conductivity as a function of $\mathrm{Pt}$ thickness. Films with complete Pt coverage fit the $R=0.1$ curve well, whereas electrically continuous films with incomplete coverage fit along the $R=0.25$ and $R=0.44$ curves. Each conductivity value is an average from 49 points measured across the $4^{\prime \prime}$ wafer.

(see the Supporting Information, Figure S7). Hence, it is safe to assume electron scattering from carbon impurity is negligible.

The electrical conductivity of all full-coverage films falls on the same $R=0.1$ curve (cf. Figure 6), suggesting that all films with complete coverage, regardless of the nucleation layer, have a comparable number of defects and differ only in their thicknesses. Thinner films, on both nucleation layers, do not fall on this same curve. As Pt surface roughness is similar for all contiguous films, this deviation on thinner films is a result of gaps between adjacent Pt islands. The gaps can be regarded as "grain boundaries," but with a higher potential barrier than that found between adjoining grains. Thus, by increasing $R$ to account for this higher barrier, the electrical conductivities can be well explained.

Using the same $R$ values with the Tellier-Tosser model results in a deviation between the theoretical and experimental TCR of up to $24 \%$ (Figure 7 ). Increasing $R$ to 0.21

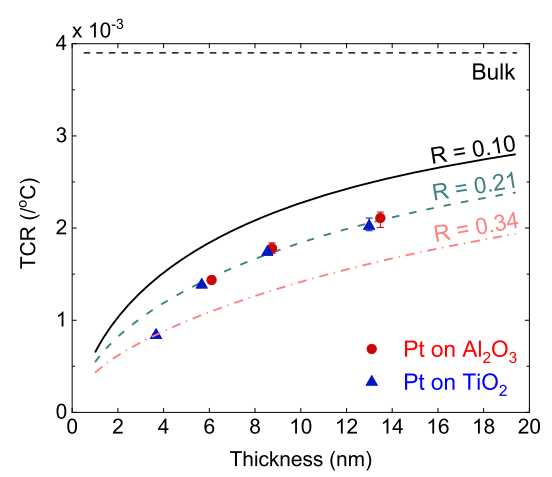

Figure 7. Experimental values and theoretical curves (with $p=0.5$ ) for TCR vs Pt thickness. Measurements from three electrical structures were averaged for each point.

substantially improves the quality of the fit. This discrepancy has been shown previously, and is likely a result of model simplifications which break down for ultrathin films as the dominant mechanism changes. ${ }^{33}$

The electrical stability of the films is crucial for any real device or sensing application. ${ }^{41-44}$ To confirm the feasibility of these films for such applications, the RMS voltage stability of each film was measured (see the Supporting Information, 
Figure S8). All films were found to have an RMS film stability within $50 \mathrm{ppm}$. These results are comparable to those reported previously for $50 \mathrm{~nm}$ PEALD Pt films. ${ }^{45}$ Hence, the use of these films in devices is very promising.

\section{CONCLUSIONS}

In this work, we have shown that electrically continuous $\mathrm{Pt}$ films thinner than $4 \mathrm{~nm}$ can be deposited using PEALD with $\mathrm{TiO}_{2}$ as a nucleation layer. We compared the nucleation behavior of $\mathrm{Pt}$ on two different nucleation layers, $\mathrm{Al}_{2} \mathrm{O}_{3}$ and $\mathrm{TiO}_{2}$. Our results suggest that reducible metal oxides promote Pt nucleation by acting as an oxygen reservoir, thereby allowing the formation of thinner, electrically continuous films. The electrical conductivity and TCR of these ultrathin Pt films were reduced by up to 83 and $79 \%$ of the bulk values, respectively. The experimental electrical values were compared to the MS and Tellier-Tosser models. Both models matched the experimental data well for the films thicker than $6 \mathrm{~nm}$, indicating that PEALD Pt film properties are influenced primarily by the size effect. Additionally, electrical measurements showed good stability for all deposited films, including those which were electrically continuous but with incomplete $\mathrm{Pt}$ coverage. These results indicate that Pt films as thin as $4 \mathrm{~nm}$ can reliably be used in many device applications.

\section{ASSOCIATED CONTENT}

\section{S Supporting Information}

The Supporting Information is available free of charge on the ACS Publications website at DOI: 10.1021/acsami.8b21054. Additional figures (PDF)

\section{AUTHOR INFORMATION}

\section{Corresponding Author}

*E-mail: karenhjkim@stanford.edu.

\section{ORCID $\odot$}

Hyo Jin K. Kim: 0000-0001-8261-5153

Peter Schindler: 0000-0002-1319-6570

Shicheng Xu: 0000-0002-0118-1611

\section{Notes}

The authors declare no competing financial interest.

\section{ACKNOWLEDGMENTS}

This work was supported by DARPA grant "N66001-16-14022" managed by Dr. Ron Polcawich. Part of this work was performed at the Stanford Nano Shared Facilities (SNSF) and Stanford Nanofabrication Facility (SNF), supported by the National Science Foundation under awards ECCS-1542152. P.S. gratefully acknowledges financial support from the Austrian Science Fund (FWF) under contract J3980-N27. The authors also thank Shirley Ahn and Soyeon Park for technical advice.

\section{REFERENCES}

(1) Colinge, J.P.; Lee, C.W.; Afzalian, A.; Akhavan, N. D.; Yan, R.; Ferain, I.; Razavi, P.; O’Neill, B.; Blake, A.; White, M.; Kelleher, A.M.; McCarthy, B.; Murphy, R. Nanowire Transistors without Junctions. Nat. Nanotechnol. 2010, 5, 225-229.

(2) Yu, B.; Chang, L.; Ahmed, S.; Wang, H.; Bell, S.; Yang, C. Y.; Tabery, C.; Ho, C.; Xiang, Q.; King, T. J.; Bokor, J.; Hu, C.; Lin, M. R.; Kyser, D. FinFET Scaling to $10 \mathrm{~nm}$ Gate Length. Digest. International Electron Devices Meeting, 2002; pp 251-254.
(3) An, J.; Kim, Y.B.; Park, J.; Gür, T. M.; Prinz, F. B. ThreeDimensional Nanostructured Bilayer Solid Oxide Fuel Cell with 1.3 $\mathrm{W} / \mathrm{cm}^{2}$ at $450{ }^{\circ} \mathrm{C}$. Nano Lett. 2013, $13,4551-4555$.

(4) Taur, Y.; Buchanan, D. A.; Chen, W.; Frank, D. J.; Ismail, K. E.; Lo, S.H.; Sai-Halasz, G. A.; Viswanathan, R. G.; Wann, H.J. C.; Wind, S. J.; Wong, H. S. CMOS Scaling into the Nanometer Regime. Proc. IEEE 1997, 85, 486-504.

(5) Wang, Y.H.; Lee, C.Y.; Chiang, C.-M. A MEMS-Based Air Flow Sensor with a Free-Standing Micro-cantilever Structure. Sensors 2007, 7, 2389-2401.

(6) Youssef, S.; Podlecki, J.; Al Asmar, R.; Sorli, B.; Cyril, O.; Foucaran, A. MEMS Scanning Calorimeter with Serpentine-Shaped Platinum Resistors for Characterizations of Microsamples. J. Microelectromech. Syst. 2009, 18, 414-423.

(7) Park, J. Y.; Kim, G. H.; Chung, K. W.; Bu, J. U. Monolithically Integrated Micromachined RF MEMS Capacitive Switches. Sens. Actuators, A 2001, 89, 88-94.

(8) Ekkels, P.; Rottenberg, X.; Puers, R.; Tilmans, H. A. C. Evaluation of Platinum as a Structural Thin Film Material for RFMEMS Devices. J. Micromech. Microeng. 2009, 19, 065010.

(9) Purkl, F.; English, T. S.; Yama, G.; Provine, J.; Samarao, A. K.; Feyh, A.; Kim, B.; O’Brien, G.; Ambacher, O.; Howe, R. T.; Kenny, T. W. Serpentine Geometry for Enhanced Performance of NanometerThin Platinum Bolometers. 2013 Transducers Eurosensors XXVII 17th Int. Conf. Solid-State Sensors, Actuators Microsystems, TRANSDUCERS EUROSENSORS 2013, 2013; pp 1507-1510.

(10) Johnson, R. W.; Hultqvist, A.; Bent, S. F. A Brief Review of Atomic Layer Deposition: From Fundamentals to Applications. Mater. Today 2014, 17, 236-246.

(11) George, S. M. Atomic Layer Deposition: An Overview. Chem. Rev. 2010, 110, 111-131.

(12) Erkens, I. J. M.; Verheijen, M. A.; Knoops, H. C. M.; Keuning, W.; Roozeboom, F.; Kessels, W. M. M. Plasma-Assisted Atomic Layer Deposition of Conformal Pt Films in High Aspect Ratio Trenches. J. Chem. Phys. 2017, 146, 052818.

(13) Zazpe, R.; Knaut, M.; Sopha, H.; Hromadko, L.; Albert, M.; Prikryl, J.; Gärtnerová, V.; Bartha, J. W.; Macak, J. M. Atomic Layer Deposition for Coating of High Aspect Ratio TiO2 Nanotube Layers. Langmuir 2016, 32, 10551-10558.

(14) Clancey, J. W.; Cavanagh, A. S.; Kukreja, R. S.; Kongkanand, A.; George, S. M. Atomic Layer Deposition of Ultrathin Platinum Films on Tungsten Atomic Layer Deposition Adhesion Layers: Application to High Surface Area Substrates. J. Vac. Sci. Technol., A 2015, 33, 01A130.

(15) Gao, F.; Arpiainen, S.; Puurunen, R. L. Microscopic SiliconBased Lateral High-Aspect-Ratio Structures for Thin Film Conformality Analysis. J. Vac. Sci. Technol., A 2015, 33, 010601.

(16) Park, S.J.; Kim, W.H.; Lee, H.B.R.; Maeng, W. J.; Kim, H. Thermal and Plasma Enhanced Atomic Layer Deposition Ruthenium and Electrical Characterization as a Metal Electrode. Microelectron. Eng. 2008, 85, 39-44.

(17) Satta, A.; Schuhmacher, J.; Whelan, C. M.; Vandervorst, W.; Brongersma, S. H.; Beyer, G. P.; Maex, K.; Vantomme, A.; Viitanen, M. M.; Brongersma, H. H.; Besling, W. F. A. Growth mechanism and continuity of atomic layer deposited $\mathrm{TiN}$ films on thermal SiO2. J. Appl. Phys. 2002, 92, 7641-7646.

(18) Thian, D.; Yemane, Y. T.; Xu, S.; Prinz, F. B. Methodology for Studying Surface Chemistry and Evolution during the Nucleation Phase of Atomic Layer Deposition Using Scanning Tunneling Microscopy. J. Phys. Chem. C 2017, 121, 27379-27388.

(19) Elam, J. W.; Nelson, C. E.; Grubbs, R. K.; George, S. M. Nucleation and growth during tungsten atomic layer deposition on $\mathrm{SiO} 2$ surfaces. Thin Solid Films 2001, 386, 41-52.

(20) Geyer, S. M.; Methaapanon, R.; Johnson, R.; Brennan, S.; Toney, M. F.; Clemens, B.; Bent, S. Structural Evolution of Platinum Thin Films Grown by Atomic Layer Deposition. J. Appl. Phys. 2014, 116, 064905.

(21) Vitos, L.; Ruban, A. V.; Skriver, H. L.; Kollár, J. The Surface Energy of Metals. Surf. Sci. 1998, 411, 186-202. 
(22) Baker, L.; Cavanagh, A. S.; Yin, J.; George, S. M.; Kongkanand, A.; Wagner, F. T. Growth of Continuous and Ultrathin Platinum Films on Tungsten Adhesion Layers Using Atomic Layer Deposition Techniques. Appl. Phys. Lett. 2012, 101, 111601.

(23) Floro, J. A.; Chason, E.; Cammarata, R. C.; Srolovitz, D. J. Physical Origins of Intrinsic Stresses in Volmer-Weber Thin Films. MRS Bull. 2002, 27, 19-25.

(24) Yoneoka, S.; Lee, J.; Liger, M.; Yama, G.; Kodama, T.; Gunji, M.; Provine, J.; Howe, R. T.; Goodson, K. E.; Kenny, T. W. Electrical and Thermal Conduction in Atomic Layer Deposition Nanobridges down to $7 \mathrm{~nm}$ Thickness. Nano Lett. 2012, 12, 683-686.

(25) Novak, S.; Lee, B.; Yang, X.; Misra, V. Platinum Nanoparticles Grown by Atomic Layer Deposition for Charge Storage Memory Applications. J. Electrochem. Soc. 2010, 157, H589.

(26) Lee, H.B.R.; Bent, S. F. Microstructure-Dependent Nucleation in Atomic Layer Deposition of Pt on $\mathrm{TiO}_{2}$. Chem. Mater. 2011, 24, 279-286.

(27) Wang, C.; Hu, L.; Poeppelmeier, K.; Stair, P. C.; Marks, L. Nucleation and Growth Process of Atomic Layer Deposition Platinum Nanoparticles on Strontium Titanate Nanocuboids. Nanotechnology 2017, 28, 185704.

(28) Mackus, A. J. M.; Leick, N.; Baker, L.; Kessels, W. M. M. Catalytic Combustion and Dehydrogenation Reactions during Atomic Layer Deposition of Platinum. Chem. Mater. 2012, 24, 1752-1761.

(29) Schindler, P.; Logar, M.; Provine, J.; Prinz, F. B. Enhanced Step Coverage of $\mathrm{TiO}_{2}$ Deposited on High Aspect Ratio Surfaces by Plasma-Enhanced Atomic Layer Deposition. Langmuir 2015, 31, $5057-5062$.

(30) Mayadas, A. F.; Shatzkes, M. Electrical-Resistivity Model for Polycrystalline Films: The Case of Arbitrary Reflection at External Surfaces. Phys. Rev. B: Solid State 1970, 1, 1382-1389.

(31) Tellier, C. R.; Tosser, A. J. The Temperature Coefficient of Resistivity of Polycrystalline Radio Frequency Sputtered Aluminium Films. Thin Solid Films 1977, 43, 261-266.

(32) Strecker, A.; Salzberger, U.; Mayer, J. Specimen Preparation for Transmission Electron Microscopy: Reliable Method for CrossSections and Brittle Materials. Prakt. Metallogr. Metallogr. 1993, 30, 482-495.

(33) Zhang, Q. G.; Zhang, X.; Cao, B. Y.; Fujii, M.; Takahashi, K.; Ikuta, T. Influence of Grain Boundary Scattering on the Electrical Properties of Platinum Nanofilms. Appl. Phys. Lett. 2006, 89, 114102.

(34) Baker, L.; Cavanagh, A. S.; Seghete, D.; George, S. M.; Mackus, A. J. M.; Kessels, W. M. M.; Liu, Z. Y.; Wagner, F. T. Nucleation and Growth of Pt Atomic Layer Deposition on $\mathrm{Al}_{2} \mathrm{O}_{3}$ Substrates Using (Methylcyclopentadienyl)-Trimethyl Platinum and $\mathrm{O}_{2}$ plasma. J. Appl. Phys. 2011, 109, 084333.

(35) Nix, W. D.; Clemens, B. M. Crystallite Coalescence: A Mechanism for Intrinsic Tensile Stresses in Thin Films. J. Mater. Res. 1999, 14, 3467-3473.

(36) Elliott, S. D. Mechanism, Products, and Growth Rate of Atomic Layer Deposition of Noble Metals. Langmuir 2010, 26, 9179-9182.

(37) Tauster, S. J.; Fung, S. C.; Baker, R. T. K.; Horsley, J. A. Strong Interactions in Catalysts. Science 1981, 211, 1121-1125.

(38) Henriquez, R.; Flores, M.; Moraga, L.; Kremer, G.; GonzálezFuentes, C.; Munoz, R. C. Electron Scattering at Surfaces and Grain Boundaries in Thin Au Films. Appl. Surf. Sci. 2013, 273, 315-323.

(39) Zhang, W.; Brongersma, S. H.; Richard, O.; Brijs, B.; Palmans, R.; Froyen, L.; Maex, K. Influence of the Electron Mean Free Path on the Resistivity of Thin Metal Films. Microelectron. Eng. 2004, 76, 146-152.

(40) Liu, H.D.; Zhao, Y.P.; Ramanath, G.; Murarka, S. P.; Wang, G.C. Thickness Dependent Electrical Resistivity of Ultrathin $(<40$ nm) Cu Films. Thin Solid Films 2001, 384, 151-156.

(41) Domae, A.; Abe, T.; Kumagai, M.; Zama, M.; Oe, T.; Kaneko, N.-h. Development and Evaluation of High-Stability Metal-Foil Resistor with a Resistance of $1 \mathrm{k} \Omega$. IEEE Trans. Instrum. Meas. 2015, 64, 1490-1495.
(42) Garraud, A.; Combette, P.; Giani, A. Thermal Stability of Pt/Cr and $\mathrm{Pt} / \mathrm{Cr}_{2} \mathrm{O}_{3}$ Thin-Film Layers on a $\mathrm{SiN}_{\mathrm{x}} / \mathrm{Si}$ Substrate for Thermal Sensor Applications. Thin Solid Films 2013, 540, 256-260.

(43) Rui, Y.F.; Liu, J.Q.; Yang, B.; Yang, C.S.; Wei, D.X. Mechanical and Electrical Stability of Parylene-Based Platinum-Black Coated Wire Microelectrode for Implantable Applications. J. Appl. Electrochem. 2013, 43, 301-308.

(44) Felipe, T. S.; Murarka, S. P.; Ajayan, P. M.; Bonevich, J. Electrical Stability and Microstructural Evolution in Thin Films of High Conductivity Copper Alloys. Proceedings of the IEEE 1999 International Interconnect Technology Conference, 1999; pp 293-295.

(45) Everhart, C. L. M.; Kaplan, K. E.; Winterkorn, M. M.; Kwon, H.; Provine, J.; Asheghi, M.; Goodson, K. E.; Prinz, F. B.; Kenny, T. W. High Stability Thermal Accelerometer Based on Ultrathin Platinum ALD Nanostructures. 2018 IEEE Micro Electro Mechanical Systems (MEMS), 2018; pp 976-979. 